Schulich School of Law, Dalhousie University

Schulich Law Scholars

2020

Next Generation Environmental Assessment in the Emerging High Seas Regime? An Evaluation of the State of the Negotiations

Meinhard Doelle

Gunnar Sander

Follow this and additional works at: https://digitalcommons.schulichlaw.dal.ca/scholarly_works

Part of the Environmental Law Commons 


\section{The International Journal of Marine and Coastal Law}

\section{Next Generation Environmental Assessment in the Emerging High Seas Regime? An Evaluation of the State of the Negotiations

\author{
--Manuscript Draft--
}

\begin{tabular}{|c|c|}
\hline \multicolumn{2}{|l|}{ Manuscript Number: } \\
\hline Full Title: & $\begin{array}{l}\text { Next Generation Environmental Assessment in the Emerging High Seas Regime? An } \\
\text { Evaluation of the State of the Negotiations }\end{array}$ \\
\hline Article Type: & Special Issue: Arctic Environmental and Climate Change Governance \\
\hline \multicolumn{2}{|c|}{ Corresponding Author's Institution: } \\
\hline First Author: & Meinhard Doelle \\
\hline Order of Authors: & Meinhard Doelle \\
\hline Keywords: & $\begin{array}{l}\text { Environmental Assessment } \\
\text { Environmental Impact Assessment } \\
\text { Strategic Environmental Assessment (SEA) } \\
\text { Regional Environmental Assessment (REA) } \\
\text { Areas Beyond National Jurisdiction } \\
\text { Biodiversity Beyond National Jurisdiction }\end{array}$ \\
\hline
\end{tabular}




\title{
Next Generation Environmental Assessment in the Emerging High Seas Regime? An Evaluation of the State of the Negotiations
}

\author{
Meinhard Doelle \\ Canadian Chair, Marine Environmental Protection \\ World Maritime University \\ mhd@wmu.se \\ Gunnar Sander \\ Norwegian College of Fishery Science \\ University of Troms $\emptyset$, the Arctic University of Norway
}

\begin{abstract}
This article evaluates prospects for an effective Environmental assessment (EA) regime through the Biodiversity Beyond National Jurisdiction (BBNJ) process and suggests improvements to the results of the negotiations as of March 2020. We start our review by offering key elements of existing international law as it relates to EA as context. Twelve elements of "Next Generation EA" are then introduced as a standard against which the article evaluates the results of the negotiations and as inspiration for the EA elements of a new legally binding instrument. This is followed with an overview of the results of the negotiations and an evaluation of the gaps between the outcomes of the negotiations and the "Next Generation EA" standard. We conclude that the negotiations have established a reasonably solid basis for effective project level assessments, but that further improvements are needed. Much more work remains on regional and strategic assessments and the proper integration of the EA regime into effective governance of the world's oceans.
\end{abstract}

\section{Key Words}

Environmental Assessment

Environmental Impact Assessment

Strategic Environmental Assessment (SEA)

Regional Environmental Assessment (REA)

Areas Beyond National Jurisdiction

Biodiversity Beyond National Jurisdiction

\section{Introduction}

There has been considerable discussion in jurisdictions around the world, among practitioners, policy makers and academics, about the state of Environmental Assessment (EA). Academics have written extensively about the gap between the promise of EA as a 
powerful tool to shift societies toward sustainability, and its actual performance to date. ${ }^{1}$ They have explored the potential causes of this apparent gap, and how to overcome it. In debates over Canadian assessment legislation, the effort to understand and close the gap has recently been framed as "Next Generation Environmental Assessment (EA)", first in an academic initiative, ${ }^{2}$ and then a broader effort also involving practitioners and environmental organizations. ${ }^{3}$ The elements identified in this effort will be familiar to anyone immersed in the literature, and much has been written on how each element can be improved. What is new in this "Next Generation EA" work is the attempt to turn the individual elements of a strong EA process into a cohesive, interdependent package that does more than achieve incremental progress on the many individual barriers to the effectiveness of assessment processes.

The focus of much of the literature on EA has been on domestic processes dealing with human activities on land and coastal areas. Less has been written about EA in the oceans and beyond individual states. ${ }^{4}$ The ongoing negotiations on a legally binding instrument on marine biodiversity of areas beyond national jurisdiction (BBNJ) provides a rare opportunity to take the lessons learned through almost 50 years of domestic practice to design an effective international marine EA regime.

The mandate for the negotiations contains a package of four elements, one on which is the design of an environmental assessment regime for marine areas beyond national jurisdiction (ABNJ). 5 The new instrument will be an implementation agreement under the Law of the Sea Convention (LOSC). ${ }^{6}$ It aims at the conservation and sustainable use of biodiversity in any parts of the oceans and the ocean floor that are not under the jurisdiction of a state, namely the deep seabed in "the Area" and the High Seas. ${ }^{7}$ In ABNJ, all states enjoy equal rights. While

\footnotetext{
1 M Doelle, The Federal Environmental Assessment Process: A Guide and Critique (LexisNexis Butterworths, Markham, 2008); P Duinker and L Greig, 'The impotence of cumulative effects assessment in Canada: ailments and ideas for redeployment' (2006) 37(2) Environmental Management 153-161; A Morrison-Saunders, J Pope, J Cunn, A Bond and F Retief, 'Strengthening impact assessment: a call for integration and focus' (2014) 32(1) Impact Assessment and Project Appraisal2-8; A Sinclair, M Doelle and P Duinker, 'Looking up, down, and sideways: reconceiving cumulative effects assessment as a mindset' (2017) 62 Environmental Impact Assessment Review183-194.

2 R Gibson, M Doelle and A Sinclair, 'Fulfilling the promise: basic components of next generation environmental assessment' (2016) 29 Journal of Environmental Law and Practice (JELP) 257-283.

3 West Coast Environmental Law (WCEL), 'Next generation environmental assessment' in the Federal Environmental Assessment Reform Summit (Ottawa, WCEL, 2016); WCEL, 'Next generation environmental assessment' in the Federal Environmental Assessment Reform Summit II (Ottawa, WCEL, 2017).

${ }^{4} \mathrm{~N}$ Craik, M Doelle and F Gale, 'Governing information: a three dimensional analysis of environmental assessment' (2012) 90(1) Public Administration 19-36; T Koivurova,'Transboundary environmental assessment in the Arctic' (2008) 26(4) Impact Assessment and Project Appraisal 265-275; R Warner, 'Environmental assessments in the marine areas of the polar regions' in E Molenaar, A Elferink and D Rothwell (eds), Polar Regions: Interactions Between Global and Regional Regimes (Martinus Nijhoff Publishers, Leiden, 2013) 139-162.

${ }^{5}$ United Nations General Assembly (UNGA), Resolution on Internationally legally binding instrument under United Nations Convention on the Law of the Sea, A/RES/72/249, 24 December 2017.

${ }^{6}$ United Nations Convention on the Law of the Sea (Montego Bay, 10 December 1982, in force November 1994) 1833 UNTS 396.

7 Ibid., at arts. 1(1), 86, 133-155.
} 
this is commonly associated with the freedom of the high seas and a void of regulation, ABNJ are actually subject to a complex regulatory system that includes a variety of negotiated agreements and international organisations, which the negotiations must take into consideration.

The objective of this article is to evaluate prospects for an effective EA regime through the BBNJ process and to suggest improvements. In addition to EA, there are three other elements in the negotiating package, marine genetic resources (and access and benefit sharing), areabased management tools (including marine protected areas), and capacity-building and transfer of marine technology. These other elements are only considered in this article to the extent that they have clear implications for the EA regime.

We start our review of the state of the negotiations by considering key elements of the existing international legal regime for EAs. Twelve elements of "Next Generation EA" are then offered and explored as a standard against which to assess the state of the negotiations and as inspiration for a new legally binding instrument. This is followed with an overview of the current state of the negotiations, explored through formal submissions made to date and the state of the negotiations as of March, 2020.8 We then offer an evaluation of the gaps between the current state of the negotiations and the "Next Generation EA" standard, and some concluding thoughts on how the new instrument could evolve through the ongoing negotiations and implementation to meet the "Next Generation EA" standard.

Writing about environmental and other impact assessments is difficult without clarity on terminology. This has been a challenge in EA literature due to the proliferation of assessment tools with a plethora of names and inconsistent use of terminology. ${ }^{9}$ One may categorize assessments according to: ${ }^{10}$

${ }^{8}$ UNGA, 'Draft text of an agreement under the United Nations Convention on the Law of the Sea on the conservation and sustainable use of marine biological diversity of areas beyond national jurisdiction: note by the President in Proceedings of the $3^{\text {rd }}$ Session of the International Conference on an international legally binding instrument under LOSC on the conservation and sustainable use of marine biological diversity of areas beyond national jurisdiction (New York, UNGA, A/CONF.232/2019/6, 17 May 2019) [President's Text]. While this text was drafted by the President rather than the result of negotiations, subsequent negotiations in August, 2019 appear to confirm that the text on EA generally reflect the state of the negotiations. No other significant developments on the EA negotiations were reported from this session. A revised text issued on November 27, 2019 does not include any substantive changes to the EA section. At the time of writing, the fourth and final negotiating session originally planned for March/April, 2020, has been postponed due to the COVID-19 outbreak.

${ }^{9}$ A Bond and J Pope, 'Editorial: the state of the art of impact assessment in 2012' (2012) 30(1) Impact Assessment and Project Appraisal 1-4; D Lawrence, Impact Assessment: Practical Solutions to Recurrent Problems and Contemporary Challenges (2 ${ }^{\text {nd }}$ ed., John Wiley \& Sons Inc., New Jersey, 2013); Morrison-Saunders et.al (n1).

${ }^{10} \mathrm{G}$ Sander, 'International legal obligations for environmental impact assessment and strategic environmental assessment in the Arctic Ocean' (2016) 31(1) The International Journal of Marine and Coastal Law (IJMCL) 88119. 
- the object of assessment with related differences in assessment tools: regional assessments and strategic assessments of policies, plans and programmes versus assessments of concrete projects;

- the thematic scope or concern of assessments, ranging from a focus on a narrow range of issues, such as biophysical or socioeconomic impacts, to integrated assessments considering all impacts;

- the jurisdictional scope: domestic within one national state or transboundary, involving other states' territories or ABNJ

In this article, we use Environmental Assessment (EA) as a broad category encompassing Strategic Environmental Assessment (SEA), Regional Environmental Assessments (REA) and project level Environmental Impact Assessment (EIA). ${ }^{11}$ REA is often considered a subset of SEA. However, REA has an important function in an environmental governance system that makes it quite separate and distinct from SEA. A REA, as we conceive of it, assesses the status and trends of the ecosystem in a given region, taking into account the cumulative impacts of all past and future human activities. Thus, the object to be assessed is the ecosystem and its biodiversity, not a specific initiative for strategic action. However, through the understanding of the state of ecosystems and how they interact with human activities, a REA should identify priorities for action and limits on human activities. ${ }^{12}$

The use of the term "environment" may suggest a preference for assessing biophysical impacts. However, the definitions of environment in EA instruments vary considerably, and many include social and economic impacts. EIA, SEA and REA as defined here can include a broad range of social and economic concerns and can even become integrated impact assessment tools that consider all impacts, benefits, risks and uncertainties. As will be seen, defining the scope of assessments along all three dimensions is one of the key challenges facing the negotiations.

Finally, this article is published in a special issue that is focused on Arctic issues, so a few words about the regional relevance of the negotiations on EA are warranted. The Arctic states have a long engagement in advocating good EIAs adapted to the region, though only as non-binding guidelines and best practice recommendations. ${ }^{13}$ The legal EA regime for the Arctic Ocean exhibits similar weaknesses as is the case globally. This has not been compensated by regional rules due to insufficient acceptance of existing instruments and no

\footnotetext{
${ }^{11} \mathrm{R}$ Therivel and G Wood (eds), Methods of Environmental and Social Impact Assessment (4th ed., Routledge, New York, 2017); J Classon, R Therivel and A Chadwick (eds), Introduction to Environmental Impact Assessment (3 ${ }^{\text {rd }}$ edition, Routledge, New York, 2005).

${ }^{12}$ In other words, the distinction gets blurred when the status and trend assessment inevitably leads to some form of programme of action.

${ }^{13}$ Arctic Environmental Protection Strategy, Guidelines for Environmental Impact Assessment (EIA) in the Arctic (Finnish Ministry of the Environment, Helsinki, 1997); Sustainable Development Working Group, Good Practices For Environmental Impact Assessment and Meaningful Engagement in the Arctic (Arctic Council, Tromsø, 2019).
} 
attempts so far to pursue a binding regional EA agreement for the Arctic. ${ }^{14}$ The BBNJ negotiations have the potential to develop a set of global rules that remedy gaps in the global assessment regime. These will, of course, apply to the considerable portion of the Arctic Ocean that is beyond national jurisdiction to the extent that states are willing to accept them by acceding to the new instrument or they become customary international law. For the Arctic states, the potential benefit of this global approach is that the BBNJ instrument may commit more states to EA requirements in the Arctic than a regional assessment treaty would have done.

\section{International Legal Instruments Relevant to EA}

The negotiations must build upon existing legal regimes. To understand where improvements are warranted, we start with a review of the most relevant international law instruments. This review is also particularly relevant to the element of the negotiating mandate that stipulates that a new legally binding instrument shall not undermine existing relevant instruments. ${ }^{15}$ The negotiators are thereby mandated to consider the interplay with existing assessment obligations.

The most basic norms can be found in general principles of international environmental law that support EA. ${ }^{16}$ Most prominent is the no harm principle, which establishes the duty not to cause undue transboundary harm. A due diligence implication of the principle is that states must undertake some sort of screening of national initiatives to make sure that undue transboundary harm is identified so that it can be avoided. Other norms that give guidance to transboundary behaviour include the duty to cooperate with other states and the principle of non-discrimination between domestic and external harm. Norms on public access to information and participation play an important role for EA. The Rio Declaration, of course, established EIA as a stand-alone principle. Moreover, EA can be an important tool for the application of precaution. These general principles are combined and concretized to a varying degree in different EA systems.

International courts have ruled that EIA can be considered a customary obligation when other states or the global commons are affected. ${ }^{17}$ However, the courts have not gone into detail about what such an EIA obligation means in practice. Similar uncertainty is reflected in much of international treaty law. ${ }^{18}$ Some assessment obligations are only indirect, by not

\footnotetext{
${ }^{14}$ Sander (n10). Both the CBD and the Espoo convention mandate regional agreements on EA (see $\mathrm{p} 117$ ). It is also common that regional seas conventions contain EA obligations. However, there is none for the whole Arctic Ocean (see p 102).

${ }^{15}$ President's Text (n 8) at paras. 6-7.

${ }_{16}$ P Birnie, A Boyle and C Redgewell, International Law and the Environment (Oxford University Press, Oxford, 2009) at pp. 137-189; N. Craik The International Law of Environmental Impact Assessment. Process, Substance and Integration (Cambridge University Press, 2008) at pp. 54 -82; S.A. Atapattu, Emerging Principles of International Environmental Law (Transnational Publishers, 2008).

17 Pulp Mills on the River Uruguay (Argentina v Uruguay), Judgement, ICJ Reports 2010, p. 14, para. 204; Responsibilities and obligations of States with respect to activities in the Area, Advisory Opinion, ITLOS Reports 2011, p.10, para. 145. SEA and REA have, to date, not achieved customary status.

${ }^{18}$ Craik (n 16) at pp. 87 - 90; Sander (n 10) at p. 96.
} 
even referring explicitly to prior examination, though an assessment may be needed to meet the obligation. Other instruments explicitly require some form of "assessment", but without specifically referring to EIA or SEA. When these tools are explicitly mentioned, the precise requirements of the assessment process and resulting decisions are often not specified. However, there are also specialized EA treaties that deal with the process and substance of EA.

\section{Global Treaties}

The LOSC is the point of departure for the BBNJ negotiations. Most importantly, it establishes an obligation for States to protect and preserve the marine environment (art 192). According to art 206, Parties shall assess the potential effects of planned activities under their jurisdiction or control that may cause substantial pollution of or significant harmful changes to the environment. The reference to "activities" is general, without any exceptions, and therefore arguably covers strategic initiatives as well as concrete projects in all maritime sectors. The condition is that there is a possibility of significant harm, in this case, to the environment. The significance threshold plays a dominant role throughout domestic and international EA law. ${ }^{19}$ However, the obligation in LOSC is to "assess", there is no reference to any specific type of assessment tool.

The Convention on Biological Diversity (CBD) is important for the BBNJ negotiations due to its thematic scope. ${ }^{20}$ Art. 14 requires Parties to introduce EIA of projects and "appropriate arrangements" for assessing programs and policies, which are likely to have significant adverse impacts on biological diversity. Thus, the convention as such is more precise on the use of assessment tools than the LOSC, but requires no more from the states than the inclusion of such tools in national instruments, without any substantive direction. However, Parties have developed more detailed voluntary guidelines for addressing biodiversity in EIA and SEA. ${ }^{21}$ For the majority of states that are parties to both LOSC and CBD, CBD creates the most specific combination of direction and guidance for assessments in the oceans for all kind of activities that may affect biodiversity significantly. ${ }^{22}$ It is noteworthy that the obligations in both conventions apply to all maritime zones, and contain similar qualifying wordings related to states' different assessment capabilities. ${ }^{23}$

The International Seabed Authority (ISA) has been developing a regime for the management of the mineral resources at the deep seabed in the Area for some time. ${ }^{24}$ It has established

\footnotetext{
${ }^{19}$ Craik (n 16) at p 133, Sander (n 10) at pp $110-111$.

${ }^{20}$ United Nations Convention on Biological Diversity (Rio de Janeiro, 5 June 1992, in force 29 December 1993) 31 ILM 822, art. 14(1)a - c, and 7(c).

${ }^{21}$ COP Decision XI/18: Marine and coastal biodiversity: sustainable fisheries and addressing adverse impacts of human activities, voluntary guidelines for environmental assessment, and marine spatial planning, UNEP/CBD/COP/DEC/XI/18, October 2012.

${ }^{22}$ LOSC (n 6) at arts. 237(1) and 311(2). As of 10 Sept 2019, there were 168 parties to LOSC and 196 to CBD.

${ }^{23}$ Craik (n 16) at pp. $97-100$.

${ }^{24}$ G Le Gurun, 'Environmental impact assessment and the International seabed authority' in Bastmeijer \& Koivurova Theory and Practice of Transboundary Environmental Impact Assessment (Martinus Nijhoff Publishers, Leiden, 2008) p. 221-264; A Jaeckel, The International Seabed Authority and the Precautionary Principle (Brill, Leiden, 2017).
} 
regulations for prospecting and exploring three types of mineral resources. They contain a two-step procedure for EIA, in which a preliminary EIA and a program for environmental baseline studies is needed to obtain an exploration contract. A full EIA is required before commencing specific exploration activities listed in the rules. The assessments may need to be updated as the work proceeds. Work now is under way to prepare regulations for the exploitation phase that may follow exploration. There are also discussions about adding SEAs to the ISA regime.

The global regulations for other maritime activities are general and at times vague with respect to EA and create uneven regulations across sectors. It is debatable to what extent the global fisheries regime contains EA obligations. ${ }^{25}$ The management of fisheries contains many indirect assessment obligations, such as those embedded in requirements for the setting of quotas and closing of areas. However, the words "assess/assessments", let alone specific assessment process requirements, hardly appear in relevant instruments. An important exception is the 1995 UN Fish Stocks Agreement (UNFSA). ${ }^{26}$ It requires assessments (not necessarily through the use of EIA or SEA) of the impacts of fisheries on fish stocks and the ecosystem, and for managing new and explorative fisheries.

This implementation agreement under the LOSC is relevant for the BBNJ negotiations because of its effort to take a holistic approach to managing fish stocks and to overcome some of the challenges associated with the division of the ocean into jurisdictional zones. ${ }^{27}$ Concretely, it obliges states to conduct research and monitoring, to share the data, and to collaborate through regional fisheries management organizations or arrangements (RFMOs/As). A more recent development is the 2009 FAO guidelines for the management of deep-sea fisheries in the high seas. They apply to experimental, exploratory and on-going fisheries that that may cause significant adverse effects to vulnerable marine ecosystems on the seafloor. A series of impact assessments shall be conducted as the management regime and fisheries activities evolve. One can interpret the guidelines as a flexible framework for both SEA- and EIA-like assessments.

The London Protocol to the Dumping Convention has been the forum for the development of two peculiar assessment regimes. ${ }^{28}$ The Protocol bans dumping of wastes and other matters. However, it contains certain exceptions. ${ }^{29}$ Parties may issue a dumping permit after

\footnotetext{
25 Sander (n 10) at pp 103 - 104; R Barnes, 'The proposed LOSC implementation agreement on areas beyond national jurisdiction and its impact on international fisheries law' (2016) 31(4) The International Journal of Marine and Coastal Law 583-619.

${ }^{26}$ Agreement for the implementation of the provisions of the United Nations Convention on the Law of the Sea of 10 December 1982 relating to the conservation and management of straddling fish stocks and highly migratory fish stocks (New York, 4 August 1995, in force 11 December 2001), 2167 UNTS3 at arts 5(d), 6(3)d, 6(6) and 7(2)d. (UNFSA)

${ }^{27} \mathrm{D}$ Balton, 'Strengthening the law of the sea: the new agreement on straddling fish stocks and highly migratory fish stocks' (1996) 27 Ocean Development \& International Law 125-151; Y Tanaka, 'Zonal and integrated management approaches to ocean governance: reflections on a dual approach in international law of the sea' (2005) 19(4) IJMCL 483-514.

281996 Protocol to the Convention on the Prevention of Marine Pollution by Dumping of Wastes and Other Matter (London, 7 November 1996, in force 24 May 2006) 36 ILM1.

${ }^{29}$ Ibid at arts. 4 with Annexes and art. 9
} 
an initial audit of waste reduction as an alternative to dumping, and after an assessment of the options for disposing residual waste and their effects on living resources, human health and economics. The process requirements are open-ended, leaving it up to the individual states to apply EIAs or other relevant approaches. The parties to these instruments have also been concerned about the possibility that climate change may lead to ocean related geoengineering. They therefore have introduced a two-step procedure for ocean fertilization with an initial assessment and an environmental assessment. The aim is to decide whether applications constitute legitimate scientific interests that should be permitted. ${ }^{30}$

For other activities, there is an absence of global EA obligations beyond the general provisions of the LOSC and CBD. This includes offshore oil and gas activities, communication cables, ${ }^{31}$ shipping, aquaculture, ocean energy and bioprospecting. However, national and even regional regulations may lead to extensive assessment practices for certain of these industries.

\section{Specialised EA Law}

UNEP's "Goals and principles for EIA" from 1987 was the first international instrument defining a generic form of EIA. It includes the now well-established process steps (Fig 1) as well as requirements for the content of the EIA report. The document has been highly influential in shaping the understanding of what EIA is, even though it is not legally binding.

\footnotetext{
${ }^{30} \mathrm{R}$ Warner, 'Environment assessment in marine areas beyond national jurisdiction' in R Rayfuse (ed) Research Handbook on International Marine Environmental Law (Edward Elgar Publishers, Cheltenham, 2015) 291-312. ${ }^{31}$ A Friedman, 'Submarine telecommunication cables and a biodiversity agreement in ABNJ: finding new routes for cooperation' (2017) 32(1) IJMCL 1-35.
} 


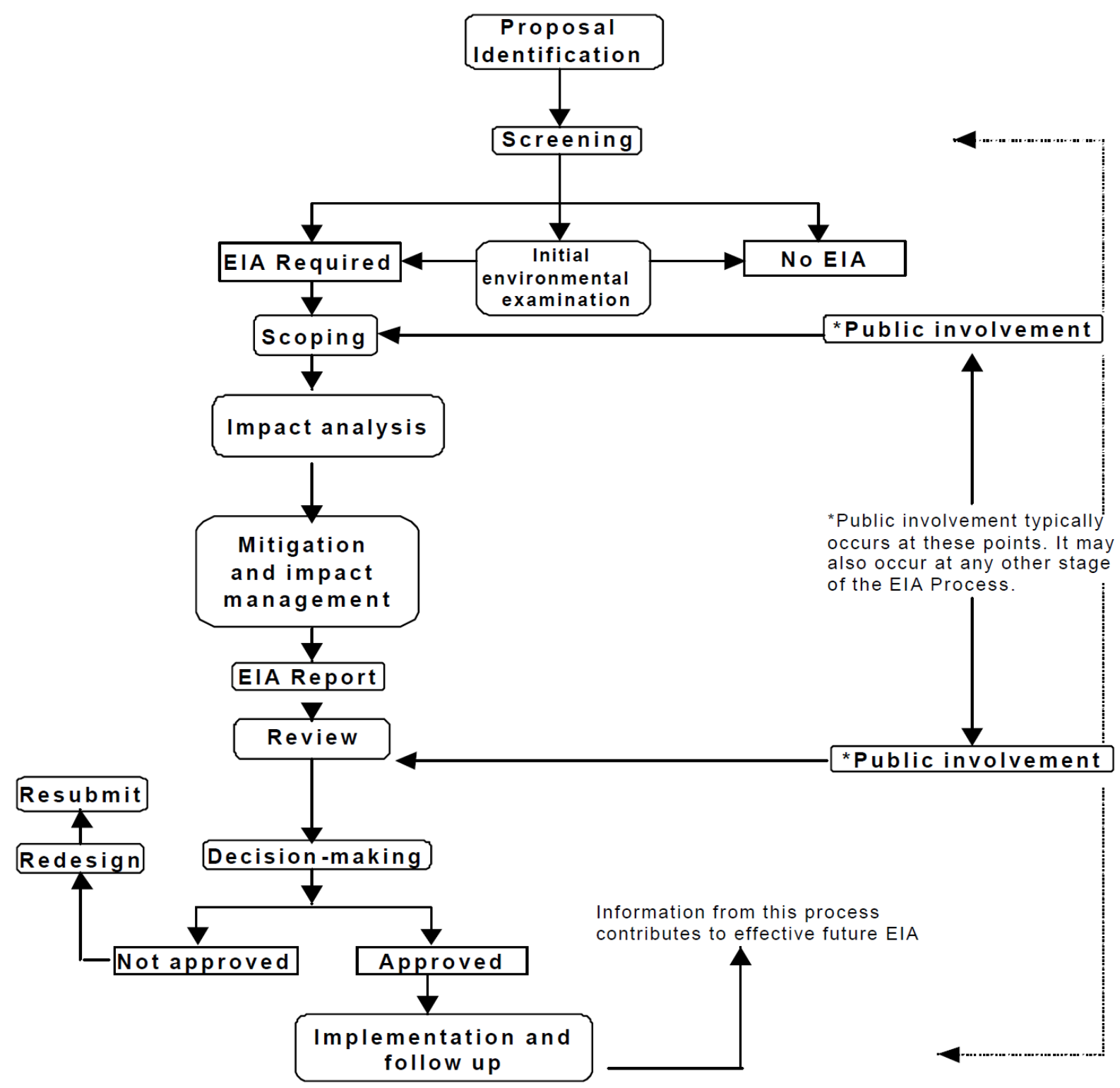

Fig 1. The generic EIA process as conceptualized by UNEP's Goals and principles for EIA. ${ }^{32}$

The Espoo Convention is the only global treaty on EA. ${ }^{33}$ The convention regulates EIA in situations where activities in one state may negatively affect the environment in other states. It obliges the state of origin to conduct an assessment in a manner that involves the affected state and its citizens by providing procedures for notification, sharing of information and consultation. The treaty also includes requirements for the content of the EIA report. The obligation to conduct an assessment is primarily triggered by listing of activities for which EIA is mandatory. The relevance in the BBNJ context is limited since it does not apply to

\footnotetext{
32 The figure was prepared by Sander (n 10), based on UNEP material

${ }^{33}$ Convention on Environmental Impact Assessment in a Transboundary Context (Espoo, 25 February 1991, in force 10 September 1997) 1989 UNTS 310. All UN member states may accede the convention after the entry into force of Amendment 1, see http://www.unece.org/index.php?id=36354.
} 
$\mathrm{ABNJ}$, and few marine activities are listed as requiring EIA. However, the transboundary procedures established, which also have contributed to shaping national EIA systems, are highly relevant for the new. BBNJ instrument.

The Kiev Protocol on SEA under the Espoo Convention similarly does not apply to ABNJ, but also contains provisions of relevance to the BBNJ negotiations. ${ }^{34}$ Plans and programs in certain listed sectors shall be assessed for their impacts on the environment and health, but only when they set the framework for future development consent for projects listed in other legislation. The Protocol only recommends the assessment of legislation and policy, reflecting a view that such initiatives are political in nature and therefore should be subject to looser assessment obligations. The Protocol codifies the commonly held view that SEA should proactively try to influence the preparation of policies, plans and programs in order to integrate environmental concerns into them at an early stage. ${ }^{35}$

\section{Regional Law}

At the regional level, the situation is more diverse. A full appreciation would require an analysis for each ocean region, considering the specific constellation of treaties and states' uneven acceptance of treaty obligations, as illustrated for the Arctic Ocean in Sander (2016). ${ }^{36}$ This is beyond the scope of this article. A few instruments, however, deserve to be highlighted:

- Most of the regional seas conventions apply only to areas within national jurisdiction (AWNJ) and contain general EA obligations that leave the specification of process and content up to the member states. Usually there are relatively loose prescriptions urging rather than obliging states to disseminate results and consult with affected parties. $^{37}$ Some conventions mandate regional monitoring as well as joint assessments. ${ }^{38}$

- Most RFMOs have updated their regulations so as to implement and concretize UNFSA's duty to assess the impacts of new and exploratory fisheries. A growing number has established targeted assessment and management procedures for the protection of vulnerable marine ecosystems on the high seas, with elements that resemble EA. 39

- The parties to the Convention on Migratory Species (CMS) have urged the use of EIA and SEA in implementing the convention's indirect assessment obligations. CMS also

\footnotetext{
34 Protocol on Strategic Environmental Assessment (Kiev, 21 May 2003, in force 11 July 2010 ) 2685 UNTS.

35 Ibid., at art. 1. EU's SEA directive art. 1 positions SEA in the same proactive role. See B Sadler (ed), Strategic Environmental Assessment at the Policy Level: Recent Progress, Current Status and Future Prospects (Ministry of the Environment, Czech Republic, 2005).

36 Sander 2018 (n 10).

37 Warner (n 30) at pp 299 - 300.

38 UNEP and IOC-UNESCO, An Assessment of Assessments, Findings of the Group of Experts. Start-up Phase of a Regular Process for Global Reporting and Assessment of the State of the Marine Environment including Socioeconomic Aspects (UNEP and IOC-UNESCO, Valletta, 2015) at pp. 61 - 71 and Annex IV Regional Summaries.

${ }^{39} \mathrm{R}$ Caddell, 'Precautionary management and the development of future fishing opportunities: the international regulation of new and exploratory fisheries' (2018) 33 IJMCL 199-260.
} 
mandates the establishment of subsidiary agreements for groups of species, covering their entire geographical range. Several of these require or recommend EIA. ${ }^{40}$

- The Madrid Protocol to the Antarctic Treaty is a specialised instrument for EIA of activities south of $60^{\circ} \mathrm{S}$, apart from fishing and whaling. ${ }^{41}$ The Protocol is interesting due to its screening provision that subjects projects to one of three EIA procedures, depending on the anticipated significance of the impacts. The individual states are responsible for the assessments, with procedures for involving other states that are highly relevant also for other ABNJ. ${ }^{42}$

- Finally, the EU directives for EIA and SEA, respectively, should be mentioned since they have shaped the EA systems of all the member states.

\section{Summary}

The existing international regime for EA in the oceans can be characterized as a fragmented patchwork of rules beyond some basic and vague obligations in customary international law, the LOSC and the CBD. Different maritime activities and ocean regions are unevenly covered by assessment obligations, and there are no specific default mechanisms that cover new activities. Compared to the need for integrated, scientifically informed ocean governance, it is problematic that SEA and REA are not covered well in international law. There are few specific rules regulating transboundary assessments involving impacts on ABNJ. Currently, there are also few specific obligations covering the High seas and the Area. A critical need therefore is to develop specific assessment rules, preferably transnational, that are applicable to all maritime zones.

\section{Elements of 'Next Generation EA'}

In this section we propose a standard against which to measure the EA process being developed in the BBNJ negotiations. Experience tells us that current domestic practice of EA is not sufficient to make EA an effective governance tool for sustainability. As explored in section 2, international law lags further behind. There is a rich literature on effective EA that is referenced in the Next Generation EA literature we draw on here. We have adapted elements of Next Generation EA (initially developed in a Canadian context) as the standard for our purposes, as it is a recent effort to develop an integrated set of elements that seem appropriately adaptable to the international marine context of the BBNJ negotiations. Gibson and others have argued that an integrated, more effective application of all key elements is needed for EA to realize its potential to become an effective governance tool for sustainability. ${ }^{43}$ While many of the key components of Next Generation EA have been discussed at length in the literature, they were generally not understood as a complete

\footnotetext{
40 Warner (n 30) at p. 297.

41 The Protocol on Environmental Protection to the Antarctic Treaty (Madrid 4 October 1991, entered into force 14 January 1998), ILM 1455.

${ }^{42}$ Ibid at art. 3, 8 and Annex I. See also K Bastmeier and R Roura, 'Enviornmental impact assessment in Antarctic' in Bastmeijer and Koivurova (n 244) 175-219.

${ }^{43}$ Gibson (n 2), 257-260.
} 
package needed to make EA effective. Jurisdictions have tended to implement some elements, but ignored others, resulting in their processes failing to deliver on the promise of EA as an effective governance tool for sustainability. The twelve components against which we assess the EA process for BBNJ are the following:

\section{Integrated, Tiered Assessments}

Planning and decision-making occur in a variety of tiers, or levels, each to be assessed by the appropriate assessment tool. Tiering includes the idea that the results from one level of assessment are transferred to another level as appropriate. ${ }^{44}$ It is our conclusion, in line with 'Next Generation EA', that three tiers of assessment are needed for an effective marine EA regime. We use the terms REA, SEA and EIA to refer to these.

A REA is a fundamental starting point for the management of biodiversity and for putting the ecosystem approach into practice. 45 REA's should be carried out wherever there is significant development pressure. REA's should consider future activities through the creation of a range of future development scenarios, and they should be clearly integrated into decision making in the assessed region, both at the policy and at the project level. SEA's assess proposed strategic initiatives, even if the proposals are not always explicitly articulated. An SEA should ensure that environmental issues are proactively incorporated into the planning process of such initiatives in order to develop policies, plans or programs that improve the interaction between human activities and natural systems. ${ }^{46}$ Finally, EIAs are project level assessments carried out within the context of the results of REAs and, as needed, SEAs.

An effective EA regime will clearly set out the role of each tier of assessment, how the role of each is properly integrated into an overall system of assessment and decision-making, and what happens at the project level when there are gaps at the regional or strategic level. Ideally, this is complemented with proper integration of the three EA tiers into planning, and into regulatory processes and decision-making systems of affected jurisdiction, institutions, businesses and communities. In other words, EA is fully integrated into an overall governance system.

\section{Cooperative Assessments}

\footnotetext{
${ }^{44} \mathrm{~J}$ Arts, P Tomlinson and H Voogd, 'Planning in tiers? Tiering as a way of linking SEA and EIA' in B Sadler, R Aschemann, J Dusik, T Fischer, M Partidario and R Verheem (eds), Handbook of Strategic Environmental Assessment (CRC Press, 2012) 415-437.

45 Sinclair et al (n 1); G Sander, 'Implementation of ecosystem-based ocean management' (PhD, Thesis, The Arctic University of Norway, 2018) at pp 26 - 31; A Borja, M Elliot, J Andersen, T Berg, J Carstensen, BS Halpern, A-S Heiskanen, S Korpinen, JS Lowndes, G Martin, N Rodriguez-Ezpeleta, 'Overview of integrative assessment of marine systems: the ecosystem approach in practice' in A. Borja, M. Elliot, M. Uyarra, J Carstensen, M. Mea Bridging the Gap Between Policy and Science in Assessing the Health Status of Marine Ecosystem (Frontiers Media, Lausanne, 2016, doi 10.3389/978-2-88945-004-6) at pp 189 - 209.

${ }^{46}$ Sinclair (n 1).
} 
A key cooperation challenge in effectively integrating EA into decision-making is how to encourage affected bodies and instruments across sectors and levels of governance to support and actively participate in the design and implementation of joint assessments. In the context of ABNJ this includes potentially affected coastal states, flag states, as well as existing bodies with decision-making responsibility in ABNJ, such as RFMO/As, the IMO, and regional seas organizations. An important starting point would be a joint REA, supported by the compilation and sharing of the underpinning data. The basic premise is that one process that actively engages all, with decision-making roles for the proposed undertaking, is the most efficient and effective way for EA to inform good decision-making. Cooperative assessments encourage mutual learning, and are more likely to lead, over time, to a common vision for the sustainability of a given region. They are also more likely to lead to informed decision-making on a proposed undertaking than other harmonization options, such as the selection of one jurisdiction or decision maker to carry out the assessment on behalf of others.

\section{Appropriate Assessment Streams}

For EA to be both effective and efficient, it needs a combination of flexibility to ensure it can adapt to undertakings with different levels of scale and complexity, along with the certainty that comes from legal clarity of what is required. There are different ways to achieve the objective of being able to tailor the process to the needs of a particular proposal to be assessed. One approach is to design different processes for large and complex, medium, and small and straight forward proposals, with criteria or lists to determine which proposal is subject to which process. An alternative is to make the process flexible and allocate discretion to an entity tasked with making process decisions to design a fit for purpose process for a given proposal, but assigning that discretion appropriately is challenging in most situations.

The most effective way to achieve an appropriate balance between flexibility and certainty is through the development of multiple process pathways with different substantive and procedural demands. This will allow for more efficient assessment of undertakings of different character, scale, potential significance of adverse effects and benefits, and potential for public interest and concern. Failure to do this effectively can lead to a narrow range of proposals being assessed, or to inefficient and ineffective processes.

\section{Co-governance with Indigenous Peoples}

In domestic contexts in many jurisdictions, indigenous rights and commitments to respect and protect them have significant implications for the design and implementation of effective EA processes. The relevance of this issue in various regions of ABNJ should be explored, and, where appropriate, EA processes need to be designed and implemented to ensure they are consistent with the commitments states have made in this regard. There is perhaps more potential in the Arctic context than elsewhere for indigenous rights to an issue given that portions of the high seas have historically been ice covered, and are therefore more likely to have been subject to indigenous occupation and use. Beyond the issues of indigenous rights 
and informed consent, this element includes the appropriate treatment of local and traditional knowledge in the assessment process.

\section{Transparency and Accountability}

Transparency and accountability are key to effective EA. The two concepts are related. Transparency seeks to ensure timely public access to information used in the assessment and access to the process itself. Those in charge of the assessment should be transparent about how they use the information gathered to reach their conclusions and recommendations to decision makers. Accountability adds an additional expectation that process and project decision makers demonstrate that they are acting in accordance with the objectives of the process, and are accountable when they do not. Accountability aims at reasoned decisions and recourse to challenge decisions. These elements are critical for effective EA because of the persistence of broad discretion in the EA process and decisionmaking. Transparency and accountability combine to provide a critical counterbalance to discretion. Without them, EA risks being little more than a process to justify decisions made well before the EA process commences.

\section{Sustainability-based Assessments}

The scope of a sustainability-based assessment builds on the biophysical effects that have been the focus of traditional EA processes by adding a broad range of other impacts, benefits, risks and uncertainties to the scope of the assessment. Included in a sustainability assessment are economic effects such as employment and income, and social effects such as health impacts, gender analysis, and cultural effects. Other considerations include equity implications of the social, geographic and intergenerational distribution of predicted impacts and benefits. A key design question is the final list of sustainability criteria (including to what extent they should be guided by the sustainable development goals (SDGs)). Another important design issue is the specific trade off rules needed to decide when a net negative effect in one area can be justified by a 'greater' net benefit in another area. To be effective, a sustainability focus is required at all three levels of assessment, regional, strategic and project.

\section{Comparative Evaluation of Alternatives}

An evaluation of alternatives in comparison to a proposal is key to understanding the implications of the predicted impacts and benefits of the proposal. It is essential to good decision-making to know whether an alternative offers a more favourable mix of impacts and benefits. Key to effective alternatives assessment is the selection of appropriate alternatives to be able to assess whether there are realistic alternatives to a proposal that offer a better way forward. Alternatives considered should include the option to not proceed with a proposal, and a reasonable range of activities that show promise in achieving the same societal needs, purposes, and goals identified for the proposed activity. The best way to ensure this is to have the assessment activities integrated tightly into the planning process, and to carry out regional and SEAs prior to project based assessments. 


\section{A Cumulative Effects Mindset}

All three tiers of assessment should emphasize attention to cumulative effects. REAs (and some SEAs) are particularly appropriate for assessing cumulative effects on a larger scale. They can establish the background for EIAs assessing the additional impacts of individual projects. EAs are future looking, and thus should develop a reasonable range of future development scenarios to inform the cumulative effects analysis. Done well, this will ensure a better understanding of the interaction of the proposed undertaking with other future developments. The process should recognize that all effects are cumulative, and that any reduction in the resilience of natural systems will constrain what we can do in the future.

\section{Meaningful Public Participation}

Effective public participation requires flexibility, good judgement, and an openness to allowing public concerns to affect the outcome of an assessment. The challenge has often been that flexibility with respect to public participation is used in the name of efficiency rather than to ensure effective engagement, particularly when it comes to engaging individuals and communities with limited capacity and resources, with serious concerns about the proposal, or with cultural norms that clash with western norms of communication and engagement.

To overcome these barriers, legally binding direction is needed to ensure public engagement is effective without being so prescriptive to prevent the use of innovative public engagement tools fit for the unique circumstances of a particular case. A challenge is to find the appropriate combination of criteria and direction, while allocating appropriate discretion to those responsible for the process to make good decisions on how to most effectively engage the public. As such, effective public participation is closely connected to a number of other elements, including transparency and accountability, learning, and independence and impartiality. Public participation needs to start early in the planning process of proposed activities and continue through to the monitoring and follow-up stages of the EA process.

\section{Learning Facilitated Throughout}

The process should be designed to serve as a vehicle for mutual learning for all involved. Most importantly, perhaps, this requires more innovative engagement methods, along with a change in the mindsets of proponents, government officials, and intervenors alike. All participants need to shift from seeing EA as a battle ground to advance their interests, to a mindset that recognizes that EA provides a unique opportunity to develop common ground. A key goal of EA should be to find ways to pursue self-interest in a manner that is aligned with the interests of others and ultimately, the public interest. EA processes need to be designed to encourage this change in mindset. This includes early engagement, engagement suitable for the circumstances and those affected, a demonstrably independent and impartial process, an openness to issues of concern to those who engage, full transparency and accountability, and clear decision-making criteria.

Implementation, Monitoring and Follow-up 
While assessments predict the effects of proposed activities, monitoring actual effects of approved undertakings is an important part of an effective EA process. A follow-up program should confirm compliance with terms and conditions, and should assess the accuracy of predictions made during the course of the assessment. It will ensure enforcement action to secure compliance, and it will adjust conditions in case predictions missed or underestimated adverse impacts or overestimated benefits. It will also ensure lessons are clearly identified and passed on to make better predictions for future proposals.

\section{Independent and Impartial Administration and Assessment Review.}

This final element is about ensuring the legitimacy and impartiality of the process. It requires consideration of who is best placed to exercise discretion with respect to triggering, scope, process design, analysis and review, final decision-making and follow up. It is standard practice for many important elements of the process to be in the hands of proponents, and at times, in the hands of government decision-makers who have a vested interest in the proposal. Proponents and government decision makers are important participants in assessment processes, but the potential for bias must be understood and guarded against.

This element therefore highlights the need to ensure that those who are not impartial and independent need to be given clear direction on their role in the assessment process, along with the transparency and accountability of the decisions they make referred to above. Discretion in the implementation of the process should only be assigned to those who can reasonably be expected to exercise the discretionary power they have been granted in the public interest as defined for purposes of the EA process in question. Those who lack this independence or impartiality can still be given responsibilities in the process, but only with sufficient law and policy guidance and accountability.

\section{State of the BBNJ Negotiations on EA}

The current state of the BBNJ negotiations is the result of a long process that started well over a decade ago. The work of a Preparatory Committee was informed by submissions from negotiating blocks of parties, individual parties, and from non-state actors. ${ }^{47}$ In the first part of this section, we briefly review the key issues and diversity of preferences voiced in this initial phase. In the second part, we provide an overview of the initial President's text and try to summarize whether it has support or not, as expressed by the delegates at the third Intergovernmental Conference (IGC) in August 2019.48

\footnotetext{
47 Submissions available at https://www.un.org/depts/los/biodiversity/prepcom.htm; accessed 20 August 2019. See also UNGA, Report of the Preparatory Committee established by General Assembly Resolution 69/292: Development of an Internationally Legally Binding Instrument Document, A/AC.287/2017/PC.4/2, July 2017, available at https://www.un.org/ga/search/view doc.asp?symbol=A/AC.287/2017/PC.4/2. 48 ibid.
} 


\section{The Parties' Initial Preferences}

Five groups of parties submitted their views to the Preparatory Committee: AOSIS, CARICOM, PSIDS, the EU, and the G-77.49 Of these, the submissions from AOSIS and the G-77 were most focused on the differences between developed and developing countries, and the need for financial and technical assistance to the latter. Developing states more generally tended to emphasize equity, access to marine genetic resources and capacity-building. The environmental protection agenda that is most pronounced in the area-based management and EA elements of the negotiating package seemed to be more of a focus for developed states. All groups emphasized the need for transparency, and most included reference to other principles, such as precaution, ecosystem-based approaches, equity, and decisions based on good science. ${ }^{50}$ Some referred to common heritage or concern of human kind in some form, ${ }^{51}$ some referenced accountability, and the importance of local and traditional knowledge. 52

There was a diversity of views on whether the process should apply to proposed activities in AWNJ that may affect biodiversity in ABNJ, or only activities taking place in ABNJ. Views differed on whether the process should be triggered by thresholds, criteria, lists, or some combination. Most submissions appeared to assume that the process will be under the control of the state under whose jurisdiction or control the activity subject to assessment takes place, but there were some proposals to internationalize the process, such as by setting up an international institution to run or guide the EA process. ${ }^{53}$ Some submissions also proposed a role for the COP, including potential project decisions at the conclusion of the EA process. There was limited recognition of possible links between the EA process and other elements of the BBNJ negotiations apart from the opportunity to identify potential marine protected area (MPA) candidates through EIAs.

Initial views expressed by individual parties were as diverse as those reflected in the group submissions. Argentina highlighted its desire to see the process applied to projects in ABNJ and projects proposed in coastal areas that may affect biodiversity in ABNJ.54 Australia emphasized the responsibility of flag states to ensure EIAs are carried out, and to consult with coastal states in case of transboundary impacts. It preferred a threshold-based approach to triggering assessment, with significant effects on biodiversity as the threshold. ${ }^{55}$

\footnotetext{
${ }^{49}$ Alliance of Small Island States (AOSIS), Submission on Capacity Building and Transfer of Technology (5 December 2016); Caribbean Community (CARICOM), Submissions on Behalf of the Member States of the CARICOM (5 December 2016); Pacific Small Island Developing States (PSIDS), Submission on Institutional Arrangement (5 December 2016); EU and its Member States, Written Submission (15 February 2017); G-77 and China, Group of 77 and China's Written Submissions (5 December 2016) at the Preparatory Committee under the LOSC (n 6).

${ }^{50}$ Ibid.

${ }^{51}$ Ibid.

52 AOSIS (n 49); CARICOM (n 49); PSIDS (n 43).

53 See for example, Argentina, Written Submissions (24 April 2017) at the Preparatory Committee under the LOSC (n 6); CARICOM (n 49); EU (n 49); G-77 and China (n 49).

${ }^{54}$ Argentina, ibid.

${ }_{55}$ Australia, Written Submission (6 December 2016) at the Preparatory Committee under the LOSC (n 6) available at https://www.un.org/depts/los/biodiversity/prepcom files/rolling_comp/Australia.pdf.
} 
Canada took a similar approach, while emphasizing a number of core principles, and advocating for the respect of existing treaties and EA processes. ${ }^{56}$

China expressed a preference to not include SEA, and to not include proposed activities in coastal areas that may affect $\mathrm{ABNJ}$, noting that the obligation to address such issues is already contained in the LOS Convention. ${ }^{57}$ Mexico's submission was generally supportive of EIA and SEA, and supportive of a cooperative approach to existing regimes, institutions and legal obligations. ${ }^{58}$ Norway emphasized the value of gathering available information to inform decision-making as the greatest value of EIA. ${ }^{59}$ It proposed a combination of a list of activities that always require assessments with thresholds for other activities. It expressed support for including activities in $\mathrm{ABNJ}$ as well as in coastal waters. Russia appeared reluctant to consider including issues in the EIA process that are addressed in other regimes, citing global warming and ocean acidification as examples. ${ }^{60}$ The US generally expressed support for EIA, specifically mentioning activities under Article 206 that are proposed in coastal waters but may have effects in $A B N J$, but otherwise only offered a very general statement on EIA. ${ }^{61}$

Non-state actors who made submissions include the High Seas Alliance, the IUCN, and WWF. ${ }^{62}$ Of these, the High Seas Coalition engaged in most detail with the possible design of the EA process. It referred to a number of the principles highlighted in the submission of parties, and to best practices and existing EIA processes and guidance in multilateral and

56 Canada, Canada's Views Related to Certain Elements under Discussion by the Preparatory Committee established by UNGA Resolution 69/292 (18 December 2015), available at https://www.un.org/depts/los/biodiversity/prepcom files/rolling_comp/Canada.pdf.

57 People's Republic of China, Written Submission of the Chinese Government (7 March 2017) at the Preparatory Committee under the LOSC (n 6) at paras. 23, 24.

${ }_{58}$ Mexico, Submission by Mexico (24 April 2017) at the Preparatory Committee under the LOSC (n 6).

59 Norway, Comments by Norway (December 2016) at the Preparatory Committee under the LOSC (n 6) available at https://www.un.org/depts/los/biodiversity/prepcom files/rolling comp/Norway.pdf.

${ }^{60}$ Russian Federation, Written Submission (24 April 2017) at the Preparatory Committee under the LOSC (n 6) available at https://www.un.org/depts/los/biodiversity/prepcom files/streamlined/Russian Federation.pdf.

61 United States Delegation, Views Expressed by the US Delegation Related to Certain Key Issues Under Discussion at the Second Session of the Preparatory Committee on the Development of an International Legally Binding Instrument under the LOSC on the Conservation and Sustainable Use of Marine Biological Diversity (9 September 2016) at the Preparatory Committee under the LOSC (n 6) available at https://www.un.org/depts/los/biodiversity/prepcom files/USA Submission of Views Expressed.pdf.

${ }^{62}$ High Seas Alliance, Submission by the High Seas Alliance following the Second Session of the Preparatory Committee on the Development of an International Legally Binding Instrument under the LOSC on the Conservation and Sustainable Use of Marine Biological Diversity of Areas Beyond National Jurisdiction (22 November 2016) at the Preparatory Committee under the LOSC (n 6); International Union for Conservation of Nature (IUCN), Recommendations for the Elements of a Draft Text of an International Legally Binding Instrument under LOSC (March 2016) at the Preparatory Committee under the LOSC (n 6); WWF, Matters for Inclusion in a New International Legally-Binding Instrument under LOSC: enhanced cooperation and effective dispute resolution (March 2016) at the Preparatory Committee, $1^{\text {st }}$ Session under the LOSC (n 6); WWF, Taking a Risk Management Approach to Strategic Environmental Assessment and Environmental Impact Assessment for BBNJ (August 2016), at the Preparatory Committee, $2^{\text {nd }}$ Session under the LOSC (n 6). All available at https://www.un.org/depts/los/biodiversity/prepcom files/Prep Com webpage views submitted by delega tions.pdf. 
regional agreements. ${ }^{63}$ It proposed the goal of avoiding significant adverse impact on marine biodiversity in $\mathrm{ABN}$, and the potential of such impact, as the threshold for triggering an assessment. Responsibility should rest with the state with control over the proposed activity. It emphasized the importance of public participation, decision-making, reporting and review. Moreover, the Coalition supported SEAs and the consideration of cumulative effects. ${ }^{64}$

The IUCN did not focus on EA, but pointed to the need to integrate climate considerations into the EIA process. It also offered general support for the inclusion of EIA and SEA. ${ }^{65}$ It proposed that EIAs should be required for any activity that may adversely affect fish stocks and their environment. Finally, the WWF submission did not address EA directly, but emphasized the need for regional scale delivery for the outcomes of the negotiations to be effective. It also referred to the Sustainable Development Goals as an important measure of progress. 66

\section{The President's Initial Text and Reactions}

The focus of the President's text was generally in line with the views expressed by parties to date. It consisted of a preamble and general provisions with definitions and general principles, followed by four parts addressing the elements of "the package deal", and five final parts addressing inter alia institutional arrangements and settlement of disputes. Many of the provisions were bracketed in order to reflect the diversity of perspectives. In any event, given the status of the President's text, even un-bracketed text is still subject to the approval of states.

There were three cross-cutting issues in the text of relevance to EA. Firstly, the geographical scope of the treaty clearly has implications for the EIA process. The President suggested that "the provisions of this agreement apply to ABNJ".67 The EU was the only entity reserving its position on this, noting that some of the provisions will also be applicable to AWNJ. ${ }^{68}$ This is clearly the case in the suggested general principle of not transferring damage from one area to another, and in the provisions on transboundary assessments that keep it open whether or not to assess all activities that may have a significant impact on ABNJ, regardless of their

\footnotetext{
${ }^{63}$ High Seas Alliance, (n 62) at pp. 4-6.

64 Ibid., at p. 7.

65 IUCN (n 62).

66 WWF (n 62).

${ }^{67}$ President's text (n 8) at art. 3(1); R Lee, 'Statement by the President of the conference at the closing of the third session' in Proceedings of the Intergovernmental Conference on an Internationally Legally Binding Instrument under LOSC (n 6), (New York, UN, 2019) [President's statement]. This section is based on the May 2019 version of the President's text.

68 IISD Reporting Services, 'Summary of the third session of the Intergovernmental conference on the conservation and sustainable use of marine biodiversity of areas beyond national jurisdiction:19-30 August 2019' (2019) 25(218) Earth Negotiations Bulletin [ENB Summary Report] is the major source of information on the views of the negotiating parties. It is noteworthy that the negotiations at the IGC3 were not as transparent as before due to the use of informal meetings by delegates only, excluding many observers. The authors have consulted participants in the process.
} 
location. ${ }^{69}$ While there is broad support for the duty to assess how activities in ABNJ may affect adjacent coastal states' areas, support for assessing activities in AWNJ that affect ABNJ is more limited.

Secondly, there are ongoing discussions about the extent to which processes should be globalized under the new instrument, or whether it should constitute a framework for regional or bilateral collaboration. The institutional arrangements would include a conference of the parties with subsidiary bodies, a scientific and technical body, a secretariat and a clearing-house mechanism. ${ }^{70}$ In Part IV on EA, there are different options for the roles of these bodies, including that they may designate a pool of experts to conduct and review assessments and monitoring reports, and make decisions. ${ }^{71}$ However, it seems that there is convergence on the view that the ultimate responsibility for the assessment process lies with states. Still, there are many unresolved issues that may ultimate result in the allocation of certain roles to states, others to institutions under the new regime, and yet others potentially to existing institutions outside the regime. A related issue before negotiators is what level of detail should be specified now, and what can be delegated to the treaty bodies to be established.

Thirdly, the President's text confirmed that the agreement shall respect existing instruments and bodies. ${ }^{72}$ This was mirrored in a provision on EA, which also introduced the possibility of establishing global minimum standards for assessment. ${ }^{73}$ While this idea has support from several delegates, there has also been critical voices warning against "imposing obligations on other bodies." ${ }^{44}$ States were also concerned about how to avoid duplication of assessment work under different instruments.

Moving to Part IV on EA, the President's text outlines the key steps in a standard EIA process. Starting with screening, there are several articles describing what should trigger assessments. ${ }^{75}$ The significance threshold from the LOSC referred to above is one triggering option. The alternative is inspired by the screening procedure in the Madrid protocol ${ }^{76}$ and suggests that a simplified EIA be triggered when there is a likelihood of more than minor or transitory effects, and a comprehensive assessment when there is a risk of significant harm. There are also proposals to have lower thresholds, and/or stricter assessment procedures, for activities planned to be undertaken in ecologically significant, vulnerable or protected areas. Finally, there are suggestions for making lists of activities that normally require or do not require assessments, and different options for who should decide whether an assessment is required. Views on these issues still vary. However, there is an emerging consensus that the characteristics of an area could be considered. Even though a private proponent may actually undertake elements of the assessment, there is general agreement

${ }^{69}$ President's text (n 8) at arts 5(c), 22(3) and 26.

70 Ibid., at arts. $48-51$.

${ }^{71}$ Ibid., at arts. 32, 30.3, 37, 38, 40 and 41.

72 Ibid., at art. 4.

${ }^{73}$ Ibid., at art. 23.

${ }^{74}$ ENB Summary Report (n 68) at p. 8.

${ }_{75}$ President's text (n 8) at arts. 24, 27, 29 and 30.

${ }^{76}$ See (n 41) 
that the assessment obligation and decision-making responsibility should only rest with state parties.

The draft text proposes that states shall establish procedures to define the scope of assessments. ${ }^{77}$ This seems to have major support, though there are diverging views on whether consideration of alternatives to the proposed action should be required and on the sources of knowledge. It is still unclear whether the scope will be limited to biophysical impacts, or also include social, economic, cultural and other relevant impacts and benefits. ${ }^{78}$ Cumulative impacts are to be taken into account. ${ }^{79}$

While there seems to be agreement on the ultimate responsibility of the states for the assessment, many developing states have argued that a pool of experts may be useful for states with low capacity to conduct assessments. ${ }^{80}$ Regarding the assessment procedures, an article on public notification and consultation calls for early notification to stakeholders and effective opportunities for their participation throughout the process. ${ }^{81}$ A suggested definition of stakeholders include potentially affected states and several other specified groups. The negotiators seem to agree in principle that the process needs to be transparent and inclusive, but do not yet agree on an obligation to consider and respond to comments received. The procedures for international consultations are also controversial.

The draft text contains a long list of possible items to be included in the final assessment report. ${ }^{82}$ There are diverging views on which to include and how detailed the treaty itself should be in this regard. The negotiators seem to agree on the need to publish the key reports in the EIA process, ${ }^{83}$ but have different suggestions for how this can be done, including the role of a clearing-house mechanism and the secretariat.

The draft text includes provisions on who should review the reports, what criteria should be applied, who should make the decisions whether a planned activity may proceed, who should be responsible for monitoring and reporting the effects of authorized activities, and who should have the responsibility to adjust the terms of approval in case of unforeseen adverse impacts. ${ }^{84}$ On all these issues, the draft text as well as the views of the negotiators differ on the role of states versus international institutions, as discussed above.

Most of the articles in the draft refer to EIA. There is currently just one single article on SEA. It suggests that SEAs are to be carried out for plans and programs that meet the threshold criteria. It also suggests that the process for SEAs should follow the EIA procedures, with the

\footnotetext{
77 President's text (n 8) at art. 31(1).

78 Ibid., at arts. 31(2), 35(2)d.

${ }^{79}$ Ibid., at arts. 1, 25.

80 Ibid., at arts. 32, 35.

81 Ibid., at arts. 34.

82 Ibid., at art. 35.

83 Ibid., at art. 36.

84 Ibid., at arts. $37-41$.
} 
necessary changes (mutatis mutandis). ${ }^{85}$ There is no reference to REAs, though they may be considered to be included in the reference to SEA.

\section{Reflections on the State of the Negotiations}

It is premature to draw firm conclusions from the current text given that negotiations have not yet concluded. However, some observations are warranted based on the draft text in combination with views expressed in formal submissions and reactions to the text at negotiating session in August, 2019. ${ }^{86}$ First, it seems that there is broad support for an EIA process for activities proposed in ABNJ, but so far, no clear emerging consensus on when it would apply, what the process would look like, and how it would feed into planning and decision-making.

There are only limited signs of recognition of the potential for EA to be integrated into other elements of the BBNJ regime or into the broader global ocean regime. ${ }^{87}$ There are no concrete proposals before negotiators on how to integrate EAs into an effective overall governance regime for ABNJ. There are some who appear to view the solution as delegation or substitution in case of potential for multiple processes and multiple decision-making responsibilities, whereas others seem to favour more cooperative approaches resulting in one integrated process that informs all decision-makers.

The following table offers a snapshot of how the negotiations measure up against the 12 'Next Generation EA' elements.

\begin{tabular}{|l|l|}
\hline $\begin{array}{l}\text { Next Generation } \\
\text { Element }\end{array}$ & Status in the Negotiations \\
\hline Tiered Assessments & $\begin{array}{l}\text { Some support for the inclusion of SEA, with very limited detail } \\
\text { provided. Otherwise no recognition of tiering. REAs are not explicitly } \\
\text { identified, but could be incorporated in provisions under area-based } \\
\text { management and EA. }\end{array}$ \\
\hline Assessment Streams & $\begin{array}{l}\text { Limited recognition of the importance of designing multiple processes } \\
\text { for proposals with different levels of complexity and scale, but the } \\
\text { screening process could contribute to proper streaming if a range of } \\
\text { streams are included in the final design of the EA process. }\end{array}$ \\
\hline $\begin{array}{l}\text { Cooperative } \\
\text { Assessments }\end{array}$ & $\begin{array}{l}\text { Some recognition of the need for cooperation with coastal states, but } \\
\text { insufficient recognition of the value of cooperating with other relevant } \\
\text { actors either regionally or globally. }\end{array}$ \\
\hline
\end{tabular}

85 Ibid., at art. 28.

86 The President presented an updated text in November 2019 that did not make any substantial changes to the EA section of the text. See ENB Summary Report (n 68).

${ }^{87}$ EIA is specifically mentioned in Part II, of President's text (n 8) at art. 10(2)(f) i.e. in situ access to MGR being subject to EIA.

${ }^{88}$ President's text (n 8) at arts.17(4)d and 35(2)c 


\begin{tabular}{|c|c|}
\hline UNDRIP89 Compliant & $\begin{array}{l}\text { Not clear whether there are areas where indigenous rights extend to } \\
\text { ABNJ, but no sign of the issue having been raised. There has been } \\
\text { pressure to consider the role of indigenous knowledge in the } \\
\text { assessment process. }\end{array}$ \\
\hline $\begin{array}{l}\text { Transparent } \\
\text { Accountable }\end{array}$ & $\begin{array}{l}\text { Some recognition of the need for transparency, but not enough focus } \\
\text { to date on accountability of decision-making through criteria, } \\
\text { reasoned decision, and an ability to challenge decision made. }\end{array}$ \\
\hline $\begin{array}{l}\text { Sustainability-based } \\
\text { assessment and } \\
\text { decision-making }\end{array}$ & $\begin{array}{l}\text { Focus on biophysical impacts, with a push for a broader range of } \\
\text { impacts and benefits, but so far, no consideration of sustainability or } \\
\text { public interest test for ultimate decision-making. }\end{array}$ \\
\hline Alternatives & $\begin{array}{l}\text { Several references to alternatives, but no clear consensus for their } \\
\text { inclusion, and no clarity on the appropriate scope of alternative } \\
\text { assessments, or the importance of REAs and SEAs for the effective } \\
\text { consideration of alternatives. }\end{array}$ \\
\hline e Effects & $\begin{array}{l}\text { Strong support in principle, but no detail, and no clarity on the } \\
\text { importance of REAs and SEAs for the effective consideration of } \\
\text { cumulative effects. }\end{array}$ \\
\hline Public Participation & $\begin{array}{l}\text { Strong recognition of the importance of public participation, but the } \\
\text { complexity of public engagement in ABNJ is not adequately } \\
\text { recognized. }\end{array}$ \\
\hline Learning Oriented & No indication that mutual learning is a design consideration. \\
\hline $\begin{array}{l}\text { Monitoring } \\
\text { Follow-up }\end{array}$ & $\begin{array}{l}\text { Some recognitio } \\
\text { no clear indicati }\end{array}$ \\
\hline $\begin{array}{l}\text { Independent } \\
\text { Impartial } \\
\text { Administration }\end{array}$ & $\begin{array}{l}\text { Considerable agreement to hold states rather than proponents } \\
\text { responsible for EA, but no indication that the appropriate allocation } \\
\text { and direction of discretion to ensure a legitimate administration of the } \\
\text { process has been a priority in the negotiations. The push for } \\
\text { internationalization of (parts of) the EIA process has the potential to } \\
\text { contribute to this element. }\end{array}$ \\
\hline
\end{tabular}

\section{A Way Forward?}

In this section, we offer our thoughts possible ways forward for the negotiations. As a preliminary comment, while this article's focus is on the EA process, it is important to consider how assessments can be integrated into a broader regime for the protection and sustainable use of biodiversity. This requires better connections across the different parts of the draft treaty and the incorporation of additional elements. The existing implementation agreement under LOSC, the UNFSA, could serve as inspiration. It created a holistic framework for the management of fish stocks through mechanisms that could be applied to the management of biodiversity.

${ }^{89}$ United Nations Declaration on the Rights of Indigenous Peoples (A/RES/61/295). 
The UNFSA created a duty for states to collaborate which permeates the treaty and is spelled out in detailed requirements, especially for how to collaborate in RFMOs/As. ${ }^{90}$ Collaboration at the regional level will be key also for biodiversity since management solely by individual states and global bodies has serious limitations in terms of legitimacy, effectiveness and efficiency. ${ }^{91} \mathrm{~A}$ truly regional approach would require the creation of a broader governance regime in each region, including the option of establishing new regional fora. The BBNJ treaty should require cooperation between the relevant coastal states, states with an interest in the region and existing regional and global intergovernmental organizations, such as the Regional seas organizations, RFMOS/As, the International Seabed Authority and the International Maritime Organization. It is imperative in this regard that the ongoing discussions in the negotiations, on the reference in the mandate 'not to undermine existing relevant legal instruments', transition in tone and substance. The current battle over the scope of the mandate needs to become a constructive discussion on how to effectively integrate the BBNJ regime and its EA process into an effective overall governance system for ABNJ.

Just as the UNFSA defined assessments as a key mechanism for the management of fish stocks, ${ }^{92}$ REAs should be defined clearly in the BBNJ treaty as a mechanism of relevance for several of its elements. A regional status and trend assessment will clarify what is to be managed; it will create the basis for the use of area-based management tools, including marine protected areas; it is needed for assessing how new activities will affect biodiversity; and it may provide a basis for sustainable use of biodiversity, including marine genetic resources. Moreover, the BBNJ treaty would benefit from incorporating better mechanisms for supporting science, monitoring and sharing of data, modelled on the fisheries regime. ${ }^{93}$

In order to address the weaknesses in the international EA regime, the new treaty needs to build upon LOSC art 206 and spell out obligations that apply to all types of activities that may affect biodiversity significantly. Several techniques could be utilized to develop appropriate criteria for triggering an assessment. What should be avoided, is the exception of whole industries collectively. ${ }^{94} \mathrm{~A}$ key tool would be the creation of global minimum standards for EA, ${ }^{95}$ based on which sectoral and geographical instruments could create rules adapted to their specific needs. Just like the UNFSA and several UN resolutions have prompted RFMOS to update their mandates, this would require jurisdictions with assessment provisions to do the same. It would contribute to a more consistent approach to EA across ocean sectors and areas and reduce the risk of having to conduct different assessments for different bodies. ${ }^{96}$

\footnotetext{
${ }^{90}$ UNFSA (n 26) art 7 and Part III on international collaboration. Norway has submitted a proposal for art 6 in the draft treaty, building on a transformation of UNFSA arts 8, 9 and 10 into the context of the BBNJ negotiations.

91 J. Rochette et al, Regional oceans governance mechanisms: A review (2015) Marine Policy 60, 9 - 19.

92 UNFSA (n 26) art 5 (d)

${ }_{93}$ Compare UNFSA (n 26) arts. 5 and 6 with Annexes, with the President's text arts. 6, 15 and 51.

${ }^{94}$ There have been arguments of exempting for instance fisheries and deep seabed mining due to their coverage in existing regimes, and the cable industry due to its perceived small impacts.

95 This is one alternative option in President's text (n 8) at art. 23.
} 
Moreover, activities in AWNJ that have potential to impact ABNJ should be included in the EA process in accordance with customary international law. ${ }^{97}$ The provisions on transboundary assessments would also benefit from incorporating elements from the Espoo Convention in order to create a more unified global assessment regime. Finally, the proposal in the text to reduce decision-makers discretion to approve proposals that cause significant harm would be a significant improvement of the advisory role of EAs. ${ }^{98}$

Returning to the 12 elements of Next Generation EA, it is clear that a good number of them are explicitly recognized by parties and in the President's text. They include the elements of transparency and accountability, public participation, cumulative effects and alternatives. ${ }^{99}$ This is very encouraging. For these elements, given the high-level nature of the negotiations to date, there is every opportunity to incorporate and then implement them in a manner consistent with the 'Next Generation' approach. It will be important for the negotiations to ensure that they become important building blocks of an effective EA regime for ABNJ. The details can be worked out in the implementation rules, but a clear commitment in the treaty text is needed on the importance and meaning of these elements. 100

A second group of elements have so far not featured significantly in the negotiations, but could be integrated without too much difficulty. They include an appropriate range of assessment streams to accommodate a variety of activities, a clear commitment to sustainability, follow-up, and impartial and independent administration. We discuss each briefly here. Assessment streams could easily be included to offer some process options depending on the size, nature and complexity of the proposal being assessed. This would allow for a broader range of proposals to be assessed effectively and efficiently.

A shift from a focus on biophysical impacts to sustainability seems appropriate for ABNJ, particularly in light of the global endorsement of the sustainable development goals (SDGs). Key steps in implementing a sustainability approach would be to broaden the scope of the assessment to consider all predicted impacts and benefits, and to develop sustainabilityoriented decision-making criteria, that would result in approvals where a net contribution to sustainability is predicted. A commitment to implementing the process in a manner that is learning oriented rather than adversarial could be recognized as a guiding principle for key aspects of the process, such as public participation and follow-up. A bigger challenge will be its meaningful implementation.

Building on Articles 39 to 41 of the President's draft text, clear responsibility for an effective monitoring and follow-up program should be included, with attention to compliance, adjustments to terms and conditions, and learning for future assessments. A focus on impartial and independent decision-making, particularly with respect to broadly

\footnotetext{
${ }^{97}$ See Pulp Mills ruling (n 17) at para. 204.

98 President's text (n 8) at arts 27 and 38(2)

${ }^{99}$ See President's text (n 8) at arts 34,25 , and 35 respectively

${ }^{100}$ See, for example, President's text (n 8) at art. 25 for lack of distinct roles of REA, SEA and EIA for cumulative effects.
} 
discretionary decisions throughout the process, would further strengthen the assessment process.

While formally assigning assessment responsibility to states, the current text does not suggest a deviation from the practice of delegating much of the work to proponents. Neither does it identify or address the challenges associated with this approach, particularly the potential implications for the independence and impartiality of the EIA process. Clearly, both the proponent and the controlling state party have important roles to play in EA, but both may be insufficiently impartial to be suitable entities in control of the process. Carefully allocation of process decision-making responsibility for triggering, scoping, and conclusions and recommendations, along with clear legal direction can go a long way toward addressing this issue, and toward enhancing the legitimately and quality of the process. Ultimately, it is important to recognize that impartial and independent assessments do not take away decision making power, they rather ensure decisions are well informed and based on a common understanding of the predicted impacts, benefits, risks and uncertainties of proposed activities. Efforts by some parties toward the internationalization of the EA process offer some hope for addressing these concerns.

The President's text does not offer a clear path from the assessment to clear recommendations and conclusions on the assessed proposal, and then on to the final decision. ${ }^{101}$ Whoever makes the final decision should have the benefit of conclusions and recommendations based on the assessment, the obligation to consider them, and to justify their decision in relation to them. Among the options for the basis for the final decision are whether the proposed activity is in the public interest, whether it makes a net contribution to sustainability, whether it helps or hinders efforts under relevant global regimes, and whether it contributes to the SDGs. There is a long history of experience in domestic contexts that suggests an EIA report that simply predicts the biophysical impacts of proposed activities (without a clear connection to conclusions and recommendations and transparent and accountable decision making based on them) will do little to improve final decisionmaking.

What remains as the third group of NG elements are inter-related elements that will be more difficult to integrate into the emerging assessment process. They are the tiering of REAs, SEAs and EIAs, including their integration into planning and regulatory decision making, and cooperative assessments involving all key actors. To effectively implement the elements of tiering and cooperative assessments, the EA process for ABNJ would ideally start with a cooperative REA in each of the regions of the ABNJ. With respect to future activities, the regional assessment would not focus on individual activities, and would not be limited to activities that are proposed or are individually likely to be carried out. Rather, a key component of the regional impact assessment would be the preparation of a range of reasonable future development scenarios for the study area. As pointed out above, such a process would have significant synergies with other elements of the BBNJ negotiations and would be an important element of a more integrated regional element of an effective governance approach.

${ }^{101}$ Article 38 (n 8) offers some options in this regard. 
A key goal of the REA would be to understand how various types of activities interact with each other and the biophysical environment. This would enable decision makers to identify an appropriate combination and scale of human activities for the region. It would allow decision makers to prioritize activities that meet human needs in a way that minimize interference with the natural world, and are most consistent with sustainability. It would make it easier to focus on activities that clearly further the pursuit of the SDGs in an integrated manner, rather than place the pursuit of some at the cost of losing ground on others. Such an approach to REA could provide an important foundation for putting ecosystem-based management into practice, not leaving it as an abstract principle. Moreover, it could help build a foundation for the global UN World Ocean Assessment, and it could help get EA out of its reactive focus.

SEAs would need to be carried out proactively as needed in the face of new information that was not considered or available when REAs were carried out. Such new information could come in the form of activities not contemplated at the time the regional impact assessment was carried out, a new understanding of the health and resilience of ecosystems, or a new understanding of the benefits or impacts. SEAs would serve an important role in ensuring REAs remain current in light of evolving circumstances. SEAs would also be carried out as envisaged in the current President's text, to consider the impacts of proposed new policies, plans and programs that may have an impact on biodiversity in ABNJ. ${ }^{102}$

Project level assessments would be informed by the results of both regional and relevant strategic assessments. Project assessments would consider the impact of proposed activities, compared to a reasonable range of alternatives, in the context of preferred and likely development scenarios developed and assessed at the REA level. They would also consider efforts to meet the goals of relevant global and regional regimes and instruments such as the UN Climate Regime and the CBD and the SDGs.

A key unresolved issue is who has decision-making responsibilities for proposed activities. Leaving aside the question who will be a decision-maker in a particular situation, a desirable outcome would be a cooperative approach to decision-making involving all decision makers within the regime and beyond, while ultimately each decision maker retains the responsibility to make appropriate decisions given their mandate and responsibilities.

An important part of the decision will be the terms and conditions under which proposed activities may be permitted to proceed. This then naturally leads to the importance of monitoring and follow up, including the three key roles it plays:

1. To ensure compliance (and take appropriate action in case of non-compliance),

102 M. Partidário, A strategic advocacy role in SEA for sustainability (2015), Environmental Assessment Policy and Management 17(1), 1 - 8; B. Noble and K. Nwanekezie, Conceptualizing strategic environmental assessment: Principles, approaches and research directions (2017), Environmental Impact Assessment Review, 62, 165-173. 
2. To verify predictions (and adapt to ensure the sustainability goals are not compromised by bad predictions), and

3. To learn from the results to improve predictions made during the course of EIAs for future assessments.

EIA experience elsewhere suggests that clear direction is needed on who is responsible, and when action needs to be taken in order to ensure the hard work done during the EIA process is not compromised through inadequate follow up.

\section{Conclusion}

The BBNJ negotiations is a rare opportunity for improving the international regime for EA, potentially having influence on assessments in AWNJ. We have characterized the existing legal regime as a fragmented patchwork on top of some basic obligations that need to be specified. We have also referred to the gap between the promise of assessments leading to more sustainable solutions and actual practice, motivating the formulation of elements of a next generation of assessments to close the gap. Both of these angles should motivate the formulation of a better regime through the BBNJ treaty.

What we can see in the current draft is that the approach to EIA has the potential to improve substantially compared to the unspecific starting point in the LOSC. There are many options available already that can accommodate changes along the lines advocated in this article. Unfortunately, the negotiators have not made much progress on improving the legal basis for strategic and regional assessments. Unless this is changed, we see the contours of a regime that has improved for the individual smaller-scale developments, but fails in capturing the larger scale systemic developments that are the main causes of deteriorating biological diversity.

It is not necessary for negotiators to work out the details of the EA process in the current negotiations. However, the basic building blocks need to be in place. They include the following:

- An effective institutional structure,

- Clarity on the respective roles of REA, SEA, and EIA,

- A broad sustainability-oriented scope,

- Meaningful public engagement,

- Effective measures to ensure the independence and impartiality of the process without undermining decision-making authority, and

- An appropriate connection between EA and other planning and decision-making in $A B N$, particularly those outside the BBNJ regime toward the effective integration of EA into an effective governance system for ABNJ. 
With such a solid foundation in the legal instrument, the parties would be able to develop details later with input from EA experts. However, without the appropriate building blocks in place in the negotiating text, there is little hope of implementing an effective EA regime for $A B N J$. The pause in the negotiations due to the corona crisis, and the prospect of extending them beyond the planned fourth negotiation session offers an opportunity to ensure the basic building blocks are in place, and perhaps to start to develop at least some of the detail needed to ensure that an effective EA regime emerges. 